\title{
Health and ageing in Nairobi's informal settlements-evidence from the International Network for the Demographic Evaluation of Populations and Their Health (INDEPTH): a cross sectional study
}

Boniface Wilunda ${ }^{1 *}$, Nawi $\mathrm{Ng}^{2,3}$ and Jennifer Stewart Williams ${ }^{2}$

\begin{abstract}
Background: Much of the focus on population ageing has been in high-income counties. Relatively less attention is given to the world's poorest region, Sub-Saharan Africa (SSA) where children and adolescents still comprise a high proportion of the population. Yet the number of adults aged 60-plus in SSA is already twice that in northern Europe. In addition, SSA is experiencing massive rural to urban migration with consequent expansion of informal urban settlements, or slums, whose health problems are usually unrecognised and not addressed. This study aims to improve understanding of functional health and well-being in older adult slum-dwellers in Nairobi (Kenya).

Methods: The study sample comprised men and women, aged 50 years and over, living in Korogocho and Viwandani, Nairobi, Kenya $(n=1,878)$. Data from the International Network for the Demographic Evaluation of Populations and Their Health (INDEPTH) and the WHO Study on global AGEing and adult health (SAGE Wave 1) were analysed. The prevalence of poor self-reported quality of life (QoL) and difficulties in domain-specific function is estimated by age and sex. Logistic regression investigates associations between difficulties in the domains of function and poor QoL, adjusting for age, sex and socio-demographic factors. Statistical significance is set at $\mathrm{P}<0.05$.

Results: Women reported poorer QoL and greater functional difficulties than men in all domains except self-care. In the multivariable logistic regression the odds of poor QoL among respondents with problems or difficulties in relation to affect $(\mathrm{OR}=7.0 ; 95 \% \mathrm{Cl}=3.0-16.0)$, pain/discomfort $(\mathrm{OR}=3.6 ; 95 \% \mathrm{Cl}=2.3-5.8)$, cognition $(\mathrm{OR}=1.8 ; 95 \% \mathrm{Cl}=1.2-2.9)$ and mobility $(\mathrm{OR}=1.8 ; 95 \% \mathrm{Cl}=1.1-2.8)$ were statistically significant.

Conclusions: The findings underscore differences in the domains of functional health that encapsulate women and men's capacities to perform regular activities and the impact of poor functioning on QoL. Investing in the health and QoL of older people in SSA will be crucial in helping the region to realise key development goals and in opening opportunities for improved health outcomes and sustainable economic development.
\end{abstract}

Keywords: Functional health, Domains of health, Quality of life, Informal settlements, Slums, Ageing, Aging, Nairobi, Kenya, Africa

\footnotetext{
* Correspondence: bwilunda@gmail.com

${ }^{1}$ United Nations Office at Nairobi (UNON), UN Gigiri Office Complex, Block X,

P.O Box 30218-00100, Nairobi, Kenya

Full list of author information is available at the end of the article
} 


\section{Background}

Population ageing is a trend that started in developed countries where advances in medicines and technology, and economic development, have substantially reduced morbidity and delayed mortality. Between 1950 and 2010, the proportion of people aged 60 and over in the developed world increased from 12 to $22 \%$. This percentage is projected to reach $32 \%$ by 2050 . The top three countries with the highest population shares comprising people aged 60 and over in 2011 were Japan (3 $1 \%)$, Italy (27 \%) and Germany (26\%). In 2050, this ranking is expected to be Japan (42\%), Portugal (40\%) and Bosnia and Herzegovina, also $4 \%$ [1]. In low-and middle-income countries (LMICs), the share of people aged 60 and over rose from just $6 \%$ in 1950 to $9 \%$ today, and is expected to reach $20 \%$ by 2050 . However what is of significance for governments world-wide, is that between 2010 and 2050, the proportion of people who are aged 60 and over is expected to increase from 800 million to 2 billion, with 1.2 billion of these older adults living in LMICs $[1,2]$.

Ageing is as an important issue in LMICs as it is in developed countries. Yet much of the focus on population ageing has been in high-income countries. Relatively less attention has been given to ageing in the poorest region in the world - Sub-Saharan Africa (SSA) where children and adolescents still comprise a high proportion of the population. In 2011 over $40 \%$ of people in SSA were children aged under 15 years, compared with $17 \%$ in the European region and $25 \%$ in the Americas [3]. However the number of people aged 60 years and over in SSA is already twice that of older adults in northern Europe. Recent projections estimate that the portion of the population aged 60 and over in SSA will increase from 46 million in 2015 to 157 million by 2050 [1, 4].

There are over 45 developing countries in SSA. The population of these countries as a whole is over 973 million and life expectancy at birth is 57 years. Kenya is situated on the eastern part of the African continent, and is one of the more populous developing countries in SSA, with a population of almost 45 million and life expectancy at birth of 62 years [5, 6]. The annual population growth rate in Kenya was $2.6 \%$ between 2001 and 2011, compared with $2.4 \%$ in SSA. In contrast, comparative rates of population growth in the European and South-East Asian Regions were 0.3 and $1.4 \%$ respectively [7, 8]. In Kenya, people aged 60 years and over constitute about $4.7 \%$ of the total population and this figure is projected to increase to 10.4 and $26.4 \%$ by 2050 and 2100 respectively [8].

Apart from these major demographic changes, SSA is also experiencing massive rural to urban migration. This has resulted in the formation and expansion of informal urban settlements or slums $[9,10]$. About one third of the urban population in developing countries live in slums and this proportion is $62 \%$ in SSA [11]. It is expected that by 2030 , more than half of the total population of SSA will live in urban slums [12, 13]. Nairobi, the capital of Kenya, will have over two thirds of its inhabitants occupying informal urban settlements [14].

In SSA countries, older people have traditionally been respected for their wisdom and roles they play as heads of families. However in recent years, economic and social change and patterns of migration, have weakened traditional social values and networks that provide care in later life $[9,15]$. In Kenya, older people have been neglected in many of the country's policies and programmes but this is starting to change [9]. One of the Kenyan government's main population and development objectives is aimed at improving and promoting public awareness of the importance of healthy ageing and QoL [16]. Yet older adults living in urban slums exhibit poorer health and QoL compared with non-slum dwellers or their rural counterparts $[10,12]$. Studies on the health and well-being of older adults in informal settlements are necessary to fill the evidence gap in this important area.

In addition to the presence or absence of chronic illnesses that require ongoing healthcare treatment and management $[17,18]$, older adults' QoL is related to their capacity to function, physically, cognitively and emotionally on an everyday level. Functional health comprises a constellation of domains in which older adults may experience deficits, for example, in vision, mobility and cognition, that impact on their QoL. Yet although overall summary measures of functional health are important, they can overlook specific aspects and mask offsetting effects. For example, a person who scores well on cognition but poorly on pain management may have a good overall health rating. In high-income countries, there has been growing public health interest directed at improving understanding of the key components of everyday functioning so that appropriate policies and services can be developed, implemented and evaluated. This perspective is also important for low-income countries where populations are ageing rapidly and many older adults are experiencing major social and economic transitions, including migration, with little being known about their functional health and QoL $[19,20]$.

The World Health Organization (WHO) has been instrumental in promoting understanding of individuals' self-assessed 'health state' in terms of functioning and disability [21]. A common interpretation is the view that the health state reported by individuals consists of functioning in spheres or domains [22]. WHO has developed and tested eight core domains of functional health - mobility; self-care; pain/discomfort; cognition; interpersonal activities; vision; sleep/energy, and affect - which are 
widely accepted as being of fundamental importance to all human beings, irrespective of age, culture, social or socioeconomic circumstances [21, 23, 24].

This study describes domain-specific functioning and QoL in older adult slum-dwellers in Nairobi, Kenya [10, 25]. The objectives are to compare the prevalence of the WHO's self-assessed functional difficulties and poor self-reported QoL in men and women aged 50 and over, and describe associations between multiple attributes of daily function and QoL, adjusting for age, sex and socio-demographic factors.

\section{Methods}

\section{Study area and participants}

The African Population and Health Research Centre (APHRC) is implementing the longitudinal Nairobi Urban Health and Demographic Surveillance System (NUHDSS) study as part of a larger health life course study in Kenya's capital city Nairobi [26]. See http://www.indepth-network.org/Profiles/Nairobi\%20UHDSS.pdf. The NUHDSS is a member of the International Network for the Demographic Evaluation of Populations and Their Health (INDEPTH) (http://www.indepth-network.org), which comprises an international network of 52 health and demographic surveillance systems (HDSS) in 20 countries in Africa, Asia, Oceania and Central America. The NUHDSS covers large areas of Korogocho and Viwandani informal settlements or slums, located five to ten kilometres from Nairobi city centre. Compared to formal settlements, housing in informal settlements is without official approval e.g. from local authorities. Informal settlements are therefore characterized by inadequate infrustructure, poor access to basic services such as sanitation, water and electricity, and unsuitable living conditions. Since January 2003, data on core demographic events (births, deaths, migration) have been collected and updated every 4 months as part of routine NUHDSS rounds [10].

\section{Data collection}

In 2006-2007, the INDEPTH and WHO collaboration implemented the short-form of the individual INDEPTHWHO SAGE (Study on Global Ageing and Adult Health) questionnaire in the NUHDSS. Details of INDEPTHWHO SAGE are reported elsewhere. The HDSS collected data from the entire population of adults aged 50 years and over in the NUHDSS [27]. Data were collected through household visits and interviews. All interviewers were required to have had a minimum education of 12 years of schooling, reside in the NUHDSS area and have undergone training covering a 5-day period followed by 2 days of field testing. Each group of five interviewers was supervised by a team leader who conducted random spot checks on the accuracy of the information being collected and offered additional training as necessary [10]. Data were entered and cleaned at the field station in Nairobi and sent to Umeå University (Sweden) for further cleaning, imputation of missing data and harmonisation of data sets from all HDSS sites [27]. A dataset for the Nairobi NUHDSS was provided by WHO-INDEPTH and used in these analyses.

\section{Variables}

The independent variables are discrete measures of functional health in the eight WHO domains of functioning - mobility; self-care; pain and discomfort; cognition; interpersonal activities; vision; sleep/energy, and affect. They refer to the difficulties/problems faced in performing activities in each functional domain during the preceding 30 days. Responses were ranked according to a five-point Likert scale: none vs. mild vs. moderate vs. severe vs. extreme/cannot do [22]. Where responses to questions were either none, mild or moderate, respondents were classified as having 'good' functional health, and where responses were either severe and extreme or cannot do, respondents were classified as having 'poor' functional health i.e. difficulties and problems in performing associated activities [22].

The measurement of QoL is captured by the WHO Quality of Life instrument (WHOQoL) which has been used widely in low-income countries [28] and was developed by an international panel of researchers over a 12 year period. This development involved using a unique set of study protocols to ensure cross-cultural applicability and a high degree of functional and metric equivalence across different cultures and settings [19]. The WHOQoL instrument is widely used to study older adults' QoL in LMICs [27]. Quality of life refers to subjective well-being or how a person feels [19]. Functioning, on the other hand, refers to objective performance in a given domain or capacity to undertake everyday tasks within the constraints or otherwise of the domain e.g. experiencing pain or having poor vision.

The WHOQoL instrument measures the individual's subjective state using eight items asking about levels of satisfaction with various aspects of life. Self-reported responses to these questions are based on a five-point Likert scale where ' 1 ' indicates high satisfaction and ' 5 ' indicates low satisfaction. The summary index of QoL is measured on a scale of 0 (worst QoL) to 100 (best QoL). Scores were normally distributed and dichotomised using a median cut-point designating good vs. poor QoL [10]. A complete set of study instruments and questions used is available at http://www.who.int/healthinfo/sage/ indepth/en/.

Socio-demographic and economic variables are: agegroup (50-59 years, 60-69 years, 70-79 years, 80-plus 
years); sex (men, women); education (more than 6 years, less than 6 years, no formal education); marital status (in current partnership, now single); living arrangement (living with other(s), living alone); household size (1-2 members, 2-4 members, 5 members and over), and wealth quintiles as measure of socioeconomic status. A randomeffects probit model was used to estimate wealth levels based on ownership of household assets such as chairs, tables and access to electricity [24,29]. Wealth quintile 1 represents the poorest fifth of each country's respondents in terms of household asset-based wealth, and quintile 5 represents the highest (wealthiest fifth).

\section{Statistical methods}

The WHO-INDEPTH SAGE data in Kenya are weighted (using sampling weights provided by WHO-INDEPTH) to the Nairobi NUHDSS population (2007) to account for survey design and adjust for age and sex differences. All variables are categorical. Descriptive statistics are presented as weighted proportions (\%s) and weighted estimates $\left(\mathrm{n}_{\mathrm{s}}\right)$ by socio-demographic characteristics, the domains of function and QoL $[9,10]$. A breakdown of the prevalence of domain-specific functional difficulties is given by sex and age groups. Chi-squared tests of significance are used to compare sex differences in sociodemographics, the domains of function and QoL.

Multivariable logistic regression tested associations between the domain-specific functions as binary independent variables (good function vs. poor function), and QoL (good QoL vs. poor QoL). Eight separate logistic regressions were undertaken with each domain as the single independent variable and QoL as the dependent variable while adjusting for socio-demographic factors as possible confounders. We also conducted logistic regression to test the association between all the domains and QoL in the same regression, while adjusting for possible sociodemographic confounders. Socio-demographic covariates used to adjust for possible confounding were: age, sex, education, marital status, living arrangement, wealth quintiles and household size [10]. Multicollinearity was tested using the Variance Inflation Factor (VIF).

Odds ratios and $95 \%$ confidence intervals are reported. STATA Version 12 (StataCorp, 2011) was the software used for statistical analyses. The plot was constructed in R.

\section{Ethics approval}

Ethical approval was granted from the WHO ethical review committee as part of the SAGE study. In Kenya, ethical approval was granted by the Kenya Medical Research Institute (KEMRI) Ethics Committee. Informed consent was obtained from respondents prior to data collection [10].

\section{Results}

Residents of the NUHDSS, aged 50 years and over as of $1^{\text {st }}$ of October 2006, were visited. A cleaned data set of complete cases and population weights for the 2007 Nairobi NUHDSS population in Korogocho and Viwandani aged 50 -plus years was made available $(N=1,991)$. The weighted population analysed here was 1,878 .

Table 1 shows the background characteristics of men $(n=1,260)$ and women $(n=618)$ in the weighted study sample. Women tended to be older, less educated, single and living in larger households. Men were more likely than women to live alone. The prevalence of poor QoL was significantly higher in women than men. With the exception of the self-care domain, sex differences in the domains were statistically significant $(p<0.05)$ with women reporting greater functional difficulties than men.

The prevalence of poor function was higher in older age (Table 2). In the oldest age group (80-plus) men and women reported similar levels of functional difficulties. However in the 50-59, 60-69 and 70-79 year age groups, women reported significantly greater difficulties than men $(p<0.05)$ for mobility and pain/discomfort. In the 50-59 and 60-69 age groups differences between men and women were statistically significant $(p<0.05)$ for sleep/energy and affect with women also reporting greater difficulties/problems than men.

Table 3 shows higher prevalence of poor QoL with older age in both sexes, with women reporting a higher prevalence of poor QoL than men across all age groups. Differences in QoL between men and women were statistically significant $(p<0.05)$ in all age groups, except in the oldest 80-plus years group.

In separate logistic regressions, domain-specific functional difficulties were statistically significant predictors of poor QoL $(p<0.001)$ after adjusting for possible confounding by socio-demographic factors. Figure 1 shows odds ratios and $95 \%$ confidence intervals for the regression analyses. Notably, respondents reporting problems/difficulties in the affect domain were over eleven times more likely to have poor QoL (OR 11.39: $95 \%$ CI 5.37,24.15) and those reporting problems/difficulties in the pain domain were over six times more likely to have poor QoL (OR 6.51: $95 \%$ CI 4.30,9.87).

Table 4 shows the results of the multivariable logistic regression, including eight indicators of domain-specific function as independent variables in the same regression, and adjusting for socio-demographic factors as possible confounders. The odds of poor QoL among respondents with problems or difficulties for affect, pain/ discomfort, mobility and cognition were statistically significant $(p<0.05)$. Although the crude comparisons (Table 1) showed that women were significantly more 
Table 1 Background characteristics of respondents by sex, among adults aged 50 and over NUHDSS Korogocho and Viwandani Nairobi City, Kenya, 2006-7

\begin{tabular}{|c|c|c|c|c|}
\hline Variables & Men & Women & Total & $p$-value \\
\hline Total n(\%) & $1260(67.1 \%)$ & $618(32.9 \%)$ & $1878(100 \%)$ & \\
\hline Age-group n(\%) & & & & $p<0.001$ \\
\hline $50-59$ years & 909 (72.2) & $359(58.0)$ & $1271(67.6)$ & \\
\hline $60-69$ years & $250(20.0)$ & $156(25.2)$ & 404 (21.6) & \\
\hline 70-79 years & $72(5.7)$ & $62(10.1)$ & $133(7.1)$ & \\
\hline 80-plus years & $29(2.3)$ & $41(6.7)$ & $70(3.7)$ & \\
\hline Education n(\%) & & & & $p<0.001$ \\
\hline More than 6 years & $252(20.0)$ & $37(6.0)$ & $289(15.4)$ & \\
\hline Primary $<6$ years & $785(62.3)$ & $286(46.3)$ & $1071(57.0)$ & \\
\hline No formal education & $223(17.7)$ & $295(47.7)$ & $518(27.6)$ & \\
\hline Marital status n(\%) & & & & $p<0.001$ \\
\hline In current partnership & $1128(89.5)$ & $185(30.0)$ & $1313(69.9)$ & \\
\hline Now single & $132(10.5)$ & $433(70.0)$ & $565(30.1)$ & \\
\hline Living arrangement n(\%) & & & & $P<0.01$ \\
\hline Living with other(s) & $922(73.2)$ & $499(80.8)$ & $1422(75.7)$ & \\
\hline Living alone & $338(26.8)$ & $119(19.2)$ & $456(24.3)$ & \\
\hline Wealth Quintiles n(\%) & & & & $p<0.001$ \\
\hline Poorest quintile & $359(28.5)$ & $101(16.3)$ & $460(24.5)$ & \\
\hline 2nd quintile & $145(11.5)$ & $137(22.2)$ & $282(15.0)$ & \\
\hline 3rd quintile & $241(19.1)$ & $142(22.9)$ & $383(20.4)$ & \\
\hline 4th quintile & $243(19.3)$ & $151(24.6)$ & $394(21.0)$ & \\
\hline Least poorest quintile & $272(21.6)$ & $87(14.1)$ & $359(19.1)$ & \\
\hline Household size n(\%) & & & & $P<0.01$ \\
\hline 1-2 members & $570(45.2)$ & $226(36.8)$ & $797(42.4)$ & \\
\hline 3-4 members & $252(20.0)$ & $158(25.5)$ & $409(21.8)$ & \\
\hline 5 members and over & $438(34.8)$ & $234(37.8)$ & $672(35.8)$ & \\
\hline \multicolumn{5}{|c|}{ Domains of functional health \% of people reported difficulties in each domain below } \\
\hline Mobility & 5.6 & 17.4 & 9.5 & $p<0.001$ \\
\hline Self-care & 2.3 & 3.6 & 2.8 & $p=0.11$ \\
\hline Pain/Discomfort & 5.7 & 17.1 & 9.6 & $p<0.001$ \\
\hline Cognition & 6.1 & 12.7 & 8.3 & $p<0.001$ \\
\hline Interpersonal activities & 1.5 & 3.3 & 2.1 & $p=0.01$ \\
\hline Sleep/Energy & 3.9 & 10.8 & 6.2 & $p<0.001$ \\
\hline Affect & 2.6 & 8.5 & 4.6 & $p<0.001$ \\
\hline Vision & 3.3 & 7.1 & 4.5 & $p=0.001$ \\
\hline \multicolumn{5}{|l|}{ QoL } \\
\hline$\%$ with poor QoL & 36.4 & 55.2 & 42.6 & $p<0.001$ \\
\hline
\end{tabular}

Note: All analyses weighted to the Nairobi NUHDSS population 2007. P-values reported for chi-squared tests of significance comparing men and women

likely to have poorer QoL than men, this association was not statistically significant in the multivariable model. However older age was significant in association with poor QoL and respondents with relatively less education had statistically significant $(p<0.05)$ higher odds of poor QoL.

\section{Discussion}

This study has two sets of important findings. The first is in relation to age and sex-specific perceived difficulties in key domains of functional health, and the second finding refers to multivariable associations between age, sex, domain-specific functions and QoL. 
Table 2 Prevalence (\%) of poor functional health in domains by age and sex, adults aged 50 and over NUHDSS Korogocho and Viwandani Nairobi City, Kenya, 2006-7

\begin{tabular}{|c|c|c|c|c|c|c|c|c|c|c|c|c|}
\hline \multirow[b]{3}{*}{$n$} & \multicolumn{3}{|c|}{ 50-59 years } & \multicolumn{3}{|c|}{ 60-69 years } & \multicolumn{3}{|c|}{ 70-79 years } & \multicolumn{3}{|c|}{$80+$ years } \\
\hline & Men & Women & $p$-value & Men & Women & $p$-value & Men & Women & $p$-value & Men & Women & $p$-value \\
\hline & $\mathrm{i}=909$ & $n=359$ & & $n=250$ & $n=156$ & & $n=72$ & $n=62$ & & $n=29$ & $n=41$ & \\
\hline Poor heath by domains & $\%$ & $\%$ & & $\%$ & $\%$ & & $\%$ & $\%$ & & $\%$ & $\%$ & \\
\hline Mobility & 4.0 & 11.9 & $p<0.001$ & 4.2 & 17.5 & $p<0.001$ & 16.0 & 34.2 & $p=0.01$ & 39.6 & 40.2 & $p=0.96$ \\
\hline Self-care & 1.7 & 1.2 & $p=0.50$ & 2.0 & 3.5 & $p=0.33$ & 2.7 & 7.7 & $p=0.17$ & 24.7 & 18.1 & $p=0.49$ \\
\hline Pain/Discomfort & 4.1 & 11.3 & $p<0.001$ & 7.4 & 23.6 & $p<0.001$ & 10.7 & 25.6 & $p=0.02$ & 29.0 & 39.0 & $p=0.36$ \\
\hline Cognition & 4.7 & 7.3 & $p=0.06$ & 7.3 & 14.3 & $p=0.02$ & 13.3 & 26.1 & $p=0.06$ & 23.4 & 33.9 & $p=0.31$ \\
\hline Interpersonal activities & 0.8 & 1.7 & $p=0.19$ & 1.9 & 3.1 & $p=0.42$ & 1.4 & 6.6 & $p=0.11$ & 16.7 & 12.4 & $p=0.60$ \\
\hline Sleep/Energy & 2.6 & 7.5 & $p<0.001$ & 4.2 & 14.8 & $P<0.001$ & 10.7 & 13.6 & $p=0.60$ & 25.8 & 19.8 & $p=0.54$ \\
\hline Affect & 1.6 & 5.7 & $p<0.001$ & 3.4 & 11.0 & $p<0.01$ & 6.6 & 12.0 & $p=0.28$ & 17.8 & 18.5 & $p=0.94$ \\
\hline Vision & 2.3 & 3.0 & $p=0.43$ & 2.6 & 7.0 & $p=0.03$ & 9.4 & 19.1 & $p=0.10$ & 25.8 & 24.6 & $p=0.91$ \\
\hline
\end{tabular}

Note: All analyses weighted to the Nairobi NUHDSS population 2007. $P$-values reported for chi-squared tests of significance comparing men and women for each of the domain

Increasing functional difficulties/problems were reported with advancing age in both sexes and across all domains. The prevalence of functional difficulties/problems was high for mobility, pain/discomfort and cognition in respondents aged 80-plus. Difficulties/problems with self-care were highly prevalent for older men (aged 80 -plus). Sex differences in functional health were modified by age. Women aged between 50 and 79 years had significantly poorer self-perceived function than men for mobility and pain/discomfort. In the 50 to 59 year age group, women had significantly more function difficulties than men in the sleep/energy and affect domains. The finding that cognition is highly prevalent is of clinical importance given the increasing rates of dementia in older adult populations worldwide.

The significant relationships we identified between pain/ discomfort, cognition and mobility and QoL require further investigation to unravel underlying associations between the domains themselves. We can hypothesise that older adults who endure pain (for example from arthritis) may have lower mobility and a higher risk of falling. Falls

Table 3 Prevalence (\%) of poor QoL by age and sex, adults aged 50 and over NUHDSS Korogocho and Viwandani Nairobi City, Kenya, 2006-7

\begin{tabular}{lllll}
\hline & Men & Women & $p$-values & Both Sexes \\
\hline Total n (\%) & $1260(36.4)$ & $618(55.2)$ & & $1878(42.6)$ \\
Age-group n (\%) & & & & \\
50-59 years & $909(32.1)$ & $359(45.0)$ & $p<0.001$ & $1271(35.8)$ \\
60-69 years & $250(43.6)$ & $156(64.0)$ & $p<0.001$ & $404(51.4)$ \\
70-79 years & $72(50.7)$ & $62(77.5)$ & $p<0.01$ & $133(63.2)$ \\
80-plus years & $29(72.3)$ & $41(77.0)$ & $p=0.64$ & $70(75.1)$ \\
\hline
\end{tabular}

Note: All analyses weighted to the Nairobi NUHDSS population 2007. $P$-values reported for chi-squared tests of significance comparing prevalence between men and women for each age group can also lead to pain that can have impact on cognition, and poor cognition can also be a risk factor for falls. There are a range of responses and behaviours that can result from chronic pain which we did not investigate here. One current area of public health interest in older populations is that of multi-directional association between pain and alcohol i.e. does pain lead to excess alcohol consumption or does excess alcohol consumption lead to pain and where are falls on this pathway? [30-32]. The finding that cognition is highly prevalent is of clinical importance given the increasing rates of dementia in older adult populations worldwide. We did not investigate mental health but this is clearly an important area that can influence functional health.

Given evidence that intrinsic risk factors for falls include older age and female sex [33], targeting women in their 50s and 60s with falls prevention strategies may deliver benefits in this population [30]. While some cognitive decline with advancing age is attributable to biological ageing, cognition limitations impact on the ability of older persons to live independently [34]. Countries such as Kenya face major challenges in planning health and social welfare systems to cater for their ageing populations. These results underscore the need for strategies aimed at attenuating cognitive and mental decline in Nairobi's urban slum-dwellers [35].

The finding that vision, self-care, interpersonal relations, and sleep were not significant in association with QoL in the multivariable regression, suggests that associations may have been attenuated in the presence of affect, pain/ discomfort, cognition and mobility. Vision [36, 37] and sleep, for example, have been shown to be important contributors to older adults' QoL in LMICs [38, 39].

Quality of life is one of a number of complex components of successful ageing, which might be influenced by 


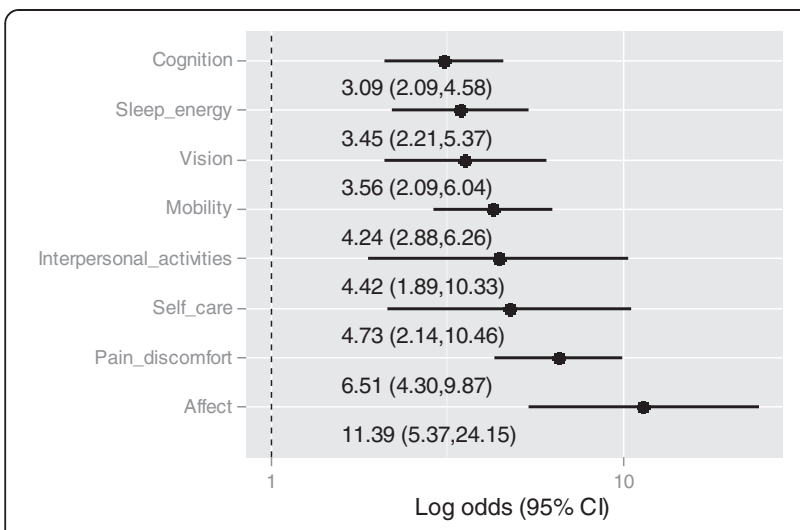

Fig. 1 Log odds \& $95 \%$ confidence intervals for multivariable logistic regressions showing associations between each domain of function and poor QoL, adults aged 50 and over NUHDSS Korogocho and Viwandani, Nairobi City, Kenya, 2006-7

different socio-demographic and lifestyle risk factors [40-43]. Other research has found that there may be interactions between sex and life-style risk factors such as obesity [42], smoking behaviour [43], and physical activity [40]. Our results show the highest odds of poor QoL in men and women with poor health in the affect domain. This is possibly because 'affect' refers to an emotional health state which has bearing on the individual's well-being and QoL [21, 23, 24]. Strategies aimed at improving QoL in this vulnerable urban population should become public health priorities.

Understanding and unravelling associations between perceived difficulties/problems with function and QoL in older adults can be challenging. Measures of overall selfreported health incorporate complex combinations and interactions between the individual's assessments of their health. Importantly this study identifies specific functional aspects of health related to poor QoL. These results show that, even after adjusting for potential confounders, difficulties/problems in relation to affect, cognition, mobility and pain/discomfort remain significant in association with poor QoL.

A single overall measure of self-reported health has been widely used in many different studies [44, 45] where it has demonstrated strong predictive power for subsequent morbidity and mortality [44, 46, 47]. However summary measures alone, can mask important aspects of health and functioning. The findings of this study underscore differences in the domains of function that encapsulate the individual's capacity to perform regular activities. An earlier study of people aged 50 and over in the INDEPTH-WHO SAGE countries reported how the domains of functional health contribute to overall health [48]. The findings from the present study confirm the differential effects of functional health on QoL among people aged 50 and over in Nairobi's slum settlements. A number of interventions aimed at improving specific aspects of everyday function in this population are feasible. Examples include physical exercise programs to improve mobility, environmental improvements to reduce the risk of falls, and social support networks to improve mental health and cognition [49].

\section{Strengths and limitations}

The domains of function developed by the WHO provide a consistent validated way of describing and comparing population health within and between countries [21-24]. However, cross-country comparison of the results need to be interpreted with caution [41]. Reporting heterogeneity of self-reported functional health across populations in different settings might mislead the comparative findings. The use of anchoring vignettes to identify and adjust for self-rated responses for reporting heterogeneity, has been advocated as a way of addressing this [50]. However the basic assumptions of vignette equivalence and response consistency are not always fulfilled. This can limit the use of anchoring vignettes for cross-country and cross-cultural comparison of self-reported health measures [51].

We acknowledge the possibility of selection bias regarding the sex and socioeconomic composition of the study sample. The study population has an age and sex distribution which is unlike the national population distribution in Kenya but is similar to the distribution in the city of Nairobi city [10]. Kyobutungi et al. [10] noted that urban settlements in Nairobi comprise mainly rural-urban migrants and in general, older females were less likely to migrate from rural areas to cities than older males. This could be because men migrate to urban areas in search of employment, while women are left behind in rural areas to take care of extended families and agriculture [52, 53]. Additionally employment opportunities in urban settlements favour younger males and the older males were relatively disadvantaged in terms of wealth [14]. The results are therefore not generalizable to the wider Kenyan population. Further analyses are needed to validate the findings in this study using other data sets.

The study population is disadvantaged in social and economic terms, being characterized by high levels of poverty and poor living conditions. The wealth quintiles report a relative gradient of wealth (or socioeconomic status) with this population. However we acknowledge that in an environment with high levels of deprivation, such as urban slums, it is possible that differences in wealth are marginal in real terms $[10,13]$.

The data are cross sectional and describe associations between health and QoL but they do not explain casual relationships. Also, this study is based on self-reported information about health. Future studies are needed to incorporate health examinations and biomarkers within household surveys in order to improve the validity of 
Table 4 Multivariable logistic regression of functional health and socio-demographic factors associated with poor QoL among adults aged 50 and over NUHDSS Korogocho and Viwandani, Nairobi City, Kenya, 2006-7 ( $N=1,878)$

\begin{tabular}{|c|c|c|c|}
\hline Functional health: reference good health & Adjusted ORs & (95\% Cls) & $p$-value \\
\hline Poor function in affect domain & 6.95 & $(3,03-15.96)$ & $p<0.001$ \\
\hline Poor function in pain/discomfort domain & 3.63 & $(2.26-5.81)$ & $p<0.001$ \\
\hline Poor function in cognition domain & 1.83 & $(1.18-2.85)$ & $p=0.01$ \\
\hline Poor function in mobility domain & 1.76 & $(1.11-2.79)$ & $p=0.02$ \\
\hline Poor function in vision domain & 1.70 & $(0.90-3.19)$ & $p=0.10$ \\
\hline Poor function in self-care domain & 1.58 & $(0.66-3.78)$ & $p=0.30$ \\
\hline Poor function in interpersonal activities domain & 1.50 & $(0.53-4.22)$ & $p=0.44$ \\
\hline Poor function in sleep/energy domain & 1.25 & $(0.71-2.19)$ & $p=0.45$ \\
\hline \multicolumn{4}{|l|}{ Sex: reference men } \\
\hline Women & 1.14 & $(0.87-1.50)$ & $p=0.33$ \\
\hline \multicolumn{4}{|l|}{ Age-group: reference $50-59$ years } \\
\hline $60-69$ years & 1.46 & $(1.14-1.86)$ & $P<0.01$ \\
\hline 70-79 years & 1.81 & $(1.22-2.69)$ & $P<0.01$ \\
\hline 80 and over & 1.80 & $(0.99-3.30)$ & $p=0.06$ \\
\hline \multicolumn{4}{|l|}{ Education reference more than 6 years } \\
\hline Primary $<6$ years & 1.40 & $(1.04-1.89)$ & $p=0.03$ \\
\hline No formal education & 1.97 & $(1.39-2.80)$ & $p<0.001$ \\
\hline \multicolumn{4}{|l|}{ Marital status: reference in current partnership } \\
\hline Now single & 1.31 & $(1.00-1.72)$ & $p=0.05$ \\
\hline \multicolumn{4}{|l|}{ Living arrangement: reference living with other(s) } \\
\hline Living alone & 1.15 & $(0.84-1.57)$ & $p=0.38$ \\
\hline \multicolumn{4}{|l|}{ Wealth quintiles: reference poorest quintile } \\
\hline 2nd quintile & 1.29 & $(0.93-1.79)$ & $p=0.13$ \\
\hline 3rd quintile & 1.30 & $(0.97-1.74)$ & $p=0.08$ \\
\hline 4th quintile & 1.07 & $(0.79-1.45)$ & $p=0.66$ \\
\hline Least poorest quintile & 0.98 & $(0.72-1.32)$ & $p=0.88$ \\
\hline \multicolumn{4}{|l|}{ Household size: reference 1-2 members } \\
\hline 3-4 members & 1.02 & $(0.74-1.40)$ & $p=0.92$ \\
\hline 5 members and over & 1.30 & $(0.97-1.74)$ & $p=0.08$ \\
\hline
\end{tabular}

Note: $\mathrm{VIF}=1.90 ; \mathrm{OR}=$ Odds ratio. $\mathrm{Cl}=$ Confidence Interval. All analyses weighted to the Nairobi NUHDSS population 2007

self-reported health states and to detect and correct systematic reporting biases [22]. Older adults are often defined as those aged 60-plus, but in this study the focus is on older adults aged 50-plus years. Although there can be distinct differences between the two age groups (e.g. in physical and cognitive function, and in regard to employment and pension eligibility) age 50 and above was appropriate here given the short life expectancy in Kenya (62 years). Another limitation is the small number of study participants aged 70 years and over who participated in the study compared to younger categories.

\section{Public health implications}

Past efforts to improve the lives of disadvantaged groups in SSA have focused on infants and children, women of reproductive age, and people with HIV/AIDS [9, 10, 54]. Yet urban slums in Nairobi and other parts of SSA are progressively accommodating disadvantaged older adult first generation rural-urban migrants and their offspring.

Older people in Kenya suffer more poverty compared to the rest of the population and elderly headed households are poorer compared to non-elderly headed households [25]. Nairobi's urban settlements are characterized by deplorable living conditions including poor housing, lack of clean water, poor sanitation and waste management and inadequate social amenities such as schools and health facilities $[26,55]$.

Substantial resources are needed to raise the health and living standards of people, particularly the older 
people in urban settlements in SSA, to come even close to that of their counterparts living in more advantaged circumstances. The persistent gender gap in health, needs to be addressed and closed. Budgets and resources are limited, and ways of measuring specific aspects of functional health, both physical and mental, will become more important in the future with regard to priority setting and resource allocation $[22,56]$. Knowledge of different aspects of health, functioning and QoL in older adult slum-dwellers in SSA will provide evidence for governments to set policy priorities, develop infrastructure, implement and evaluate interventions and ultimately assess health policies and programs within strategic frameworks. Differences between the domains of functioning are usually masked by composite measures. Many older adults suffer poor health in multiple domains. Evidence such as this is important for targeting interventions where they are needed.

Understanding the health and well-being of ageing populations is important for policy and planning, yet, research on ageing and adult health that informs policy predominantly comes from high-income countries. Deficits in everyday functional capacity lend themselves to behaviour change that can promote healthy ageing and enhance QoL. However, behavioural and lifestyle interventions are not common in LMICs, and are more typically accessed by people in high-income countries. This study provides the groundwork for further research of this type. Evidence is needed to improve understanding of associations between functional health and QoL. This can lead to informed development and evaluation of potentially cost-effective interventions suitable for lowresource settings.

\section{Conclusions}

The rapid development of urban slums accommodating increasing numbers of older adults is a serious concern for African governments as they attempt to grapple with the epidemiological transition from communicable to non-communicable diseases. This study highlights a number of areas that can be targeted to improve the physical and psychological health of older-adult slumdwellers in Nairobi, Kenya. The eight domains of functioning differently impact on QoL. Targeted interventions to improve affect, reduce body pains, enhance cognitive ability and facilitate mobility for older adults should be prioritized. Investing in the health and QoL of older people in SSA will be crucial in helping the region to realise key development goals and open up opportunities for improved health outcomes and viable sustainable economic development.

\section{Abbreviations}

APHRC: African Population and Health Research Centre; HDSS: Health and Demographic Surveillance System; INDEPTH: International Network for the
Demographic Evaluation of Populations and their Health; KEMRI: Kenya Medical Research Institute; LMICs: Low- and Middle-Income Countries; NUHDSS: Nairobi Urban Health and Demographic Surveillance System; QoL: Quality of Life; SAGE: WHO's Study on global AGEing and adult health; SSA: Sub-Saharan Africa; WHO: World Health Organization; WHOQOL: WHO Quality of Life instrument.

\section{Competing interests}

There are no competing interests to declare.

\section{Authors' contributions}

BW made a substantial contribution to the conception of the study, analyzed data, contributed to writing of the first draft of the paper. NN participated in the conception of the manuscript and provided critical inputs to the analysis and the Discussion. JSW wrote the first and last drafts and advised at all stages of the manuscript. All authors provided critical inputs to the drafts of the manuscript at all stages and approved the final draft.

\section{Authors' information}

In this work, JSW and NN were supported by the FORTE grant for the Umea Centre for Global Health Research (No. 2006-1512). NN was also supported by the project 'Paths to Healthy and Active Ageing' funded by the Swedish Research Council for Health, Working Life and Welfare, Dnr: 2013-2056. BLW was supported by the Erling Persson Family Foundation Scholarship through Umeå University. The funders had no role in study design, data collection, analysis, decision to publish, or preparation of the manuscript.

\section{Acknowledgements}

We are grateful to the WHO and the INDEPTH Network for making the WHO-INDEPTH SAGE dataset publicly available. Support for the SAGEINDEPTH Wave 1 was provided by the United States National Institute on Aging (NIA) Division of Behavioral and Social Research (BSR) through Interagency Agreements (YA1323-08-CN-0020; Y1-AG-1005-01) with WHO, covering six HDSS field sites, including the Nairobi HDSS in Kenya. We are also most grateful to our peer reviewers who provided us with important comments and feedback.

\section{Author details}

${ }^{1}$ United Nations Office at Nairobi (UNON), UN Gigiri Office Complex, Block X, P.O Box 30218-00100, Nairobi, Kenya. ${ }^{2}$ Unit of Epidemiology and Global Health, Department of Public Health and Clinical Medicine, Faculty of Medicine, Umeå University, Umeå, Sweden. ${ }^{3}$ Centre for Demographic and Ageing Research, Umeå University, Umeå, Sweden.

Received: 18 May 2015 Accepted: 1 December 2015

Published online: 11 December 2015

\section{References}

1. Beard JR, Biggs S, Bloom DE, Fried LP, Hogan P, Kalache A, et al. eds., Global Population Ageing: Peril or Promise, Geneva: World Economic Forum, 2011.

2. United Nations, Department of Economic and Social Affairs, Population Division (2013). World Population Ageing 2013. ST/ESA/SER.A/348: 95.

3. United Nations. World population prospects: The 2012 revision. Edited by Department of Economic and Social Affairs PD. New York; 2013: 118.

4. Aboderin IAG, Beard J. Older people's health in sub-Saharan Africa. Lancet. 2014;S0140-6736(14):2

5. Kenya National Bureau of Statistics, IMacro. Kenya demographic and health survey 2008-09. Calverton, Maryland: KNBS and ICF Macro; 2011.

6. World Bank Data. Sub-Saharan Africa (developing only), The World Bank Group. http://data.worldbank.org/region/SSA. Accessed 10 Dec 2015.

7. National Coordinating Agency for Population and Development: Rapid population and development. Edited by NCAPD. Nairobi: Government of Kenya; 2010: 28. http://www.healthpolicyinitiative.com/Publications/Documents/ 1096_1_kenya_brief_FINAL_4_15_10_acc.pdf. Accessed 10 Dec 2015

8. United Nations. World population prospects : The 2012 revision. New York: The United Nations Department of Economics and Social Affairs Population Division; 2013

9. Kyobutungi C, Kasiira Ziraba A, Ezeh A, Yé Y. The burden of disease profile of residents of Nairobi's slums: results from a demographic surveillance system. Popul Health Metr. 2008;6(1):8 
10. Kyobutungi C, Egondi T, Ezeh A. The health and well-being of older people in Nairobi's slums. Glob Health Action. 2010;3:2138;Suppl 2(INDEPTH WHOSAGE Supplement):45-53. doi:10.3402/gha.v3i0.2138.

11. United Nations Human Settlements Programme. State of the world's cities report 2012/2013: prosperity of cities. Nairobi: UN-HABITAT; 2012. p. 152.

12. Chepngeno G, Ezeh AC. Between a rock and a hard place: perception of older people living in Nairobi city on return-migration to rural areas. Glob Ageing. 2007:4(3):67-78.

13. Falkingham JC, Chepngeno-Langat G, Kyobutungi C, Ezeh A, Evandrou M. Does socioeconomic inequality in health persist among older people living in resource-poor urban slums? J Urban Health. 2011;88(Supp 2):S381-400.

14. Zulu EM, Beguy D, Ezeh AC, Bocquier P, Madise NJ, Cleland J, et al. Overview of migration, poverty and health dynamics in Nairobi City's slum settlements. J Urban Health. 2011:88(S2):S185-99.

15. Cohen B, Menken JE. Aging in Sub-Saharan Africa: recommendations for furthering research. Washington DC: National Academy of Sciences; 2006.

16. Olum $\mathrm{GH}$. Report on status and implementation of national policy on ageing in Kenya. Edited by (UNDESA) UNDoEaSA. Nairobi; 2003: 51.

17. Ayah RA, Joshi MD, Rosemary Wanjiru R, Njau EK, Otieno CF, Njeru EK, et al. A population-based survey of prevalence of diabetes and correlates in an urban slum community in Nairobi, Kenya. BMC Public Health. 2013;13:371.

18. Oti SI, van de Vijver SJM, Agyemang C, Kyobutungi C. The magnitude of diabetes and its association with obesity in the slums of Nairobi, Kenya: results from a cross-sectionalsurvey. Trop Med Int Health. 2013;18(12):1520-30.

19. Utsun TB, Kostanjsek N, Chatterij S, Rehm J. Measuring health and disability: manual for WHO Disability Assessment Schedule (WHODAS 2.0). Geneva, Switzerland: World Health Organization; 2010.

20. World Health Organization. Closing the gap: policy into practice on social determinants of health. In: World conference on social determinants of health. vol. Discussion Paper. Rio de Janeiro: WHO; 2011. p. 56.

21. Salomon JA, Mathers C, Chatterii S, Sadana R, Ustun TB. Quantifying individual levels of health: definitions, concepts and measurement issues. In: Murray CJL, Evans DB, editors. Health systems performance assessment debates, methods and empiricisms. Geneva: World Health Organization; 2003.

22. Hosseinpoor AR, Stewart Williams J, Itani L, Chatterji S. Socioeconomic inequality in domains of health: results from the World Health Surveys. BMC Public Health. 2012;12(198):9.

23. Chatterii S, Ustün BL, Sadana R, Salomon J, Mathers CD, Murray CJL. The conceptual basis for measuring and reporting on health. In: WHO, editor. Global Programme on Evidence for Health Policy Discussion Paper No 45. 2002. p. 20.

24. Sadana R, Tandon A, Murray CJL, Serdobova I, Cao Y, Xie W, et al. Describing population health in six domains: comparable results from 66 household surveys. World Health Organization. 2002. Accessed 10 Dec 2015 http://www.who.int/healthinfo/paper43.pdf

25. Kakwani N, Son HH, R H: Poverty, old age and social opensions in Kenya In Edited by Centre UNDP-IP; 2006: 50

26. Emina J, Beguy D, Zulu EM, Ezeh AC, Muindi K, Elung'ata P, et al. Monitoring of health and demographic outcomes in poor urban settlements: evidence from the Nairobi urban health and demographic surveillance system. J Urban Health. 2011:88(Supp 2):S200-18.

27. Kowal P, Kahn K, Ng N, Naidoo N, Abdullah S, Bawah A, et al. Ageing and adult health status in eight lower-income countries: the INDEPTH WHOSAGE collaboration. Glob Health Action. 2010;3:5302;Suppl 2(INDEPTH WHOSAGE Supplement):11-22. doi:10.3402/gha.v3i0.5302

28. Saxena S, Carlson D, Billington R, Orley J, on behalf of the WHOQOL Group. The WHO quality of life assessment instrument (WHOQOL-Bref): the importance of its items for cross-cultural research. Qual Life Res. 2001:10:711-21.

29. Howe LD, Galobardes B, Matijasevich A, Gordon D, Johnston D, Onwujekwe O, Patel R, Webb EA, Lawlor DA, Hargreaves JA: Measuring socio-economic position for epidemiological studies in low- and middle-income countries: a methods of measurement in epidemiology paper. Int J Epidemiol. 2012; 41(3):871-86. doi:10.1093/ije/dys037:16

30. World Health Organization. WHO global report on falls prevention in older age. Geneva: World Health Organization; 2008.

31. Zale EL, Maisto SA, Ditre JW. Interrelations between pain and alcohol: an integrative review. Clin Psychol Rev. 2015;37:57-71.

32. Stewart Williams J, Kowal P, Hestekin H, O'Driscoll T, Peltzer K, Yawson A, et al. Prevalence, risk factors and disability associated with fall-related injury in older adults in low- and middle-incomecountries: results form the WHO Study on global AGEing and adult health (SAGE). BMC Med. 2015;13(147):12.
33. Karlsson MK, Magnusson H, von Schewelov T, Rosengren BE. Prevention of falls in the elderly - a review. Osteoporos Int. 2013;24(3):747-62.

34. Muir SW, Gopaul K, Montero Odasso MM. The role of cognitive impairment in fall risk among older adults: a systematic review and meta-analysis. Age Ageing. 2012;41(3):299-308

35. Bloom DE, Mahal A, Rosenberg L. Design and operation of health systems in developing countries. Chapter 13. In: Global population ageing: Peril or promise? Geneva: World Economic Forum; 2012. p. 148

36. Baltussen R, Smith A. Cost effectiveness of strategies to combat vision and hearing loss in sub-Saharan Africa and South East Asia: mathematical modelling study. BMJ. 2012;344:12.

37. Akuamoah-Boateng $\mathrm{H}$. Self-reported vision health status among older people in the Kassena-Nankana District, Ghana. Glob Health Action. 2013;6: 19012. doi:10.3402/gha.v6i0.19012.

38. Gildner TE, Liebert MA, Kowal P, Chatterji S, Snodgrass JJ. The Study on Global Ageing and Adult Health (SAGE): The effect of self-reported sleep quality and duration on cognitive function among older adulrs from six middle income countries. Am J Hum Biol. 2013;25(2):259. 38th American Human Biology Assocation Conference Proceedings.

39. Gildner TE, Liebert MA, Kowal P, Chatterji S, Snodgrass J. Associations between sleep duration, sleep quality, and cognitive test performance among older adults from six middle income countries: results from the Study on Global Ageing and Adult Health (SAGE). J Clin Sleep Med. 2014;10(6):9.

40. Morimoto T, Oguma Y, Yamazaki S, Sokejima S, Nakayama T, Fukuhara S. Gender differences in effects of physical activity on quality of life and resource utilization. Qual Life Res. 2006;15(3):537-46.

41. Ng N, Hakimi M, Byass P, Wilopo S, Wall S. Health and quality of life among older rural people in Purworejo District, Indonesia. Global Health Action 2010;3:2125, Suppl (INDEPTH WHO-SAGE Supplement):78-87. doi:10.3402/ gha.v3i0.2125

42. Choo J, Jeon S, Lee J. Gender differences in health-related quality of life associated with abdominal obesity in a Korean population. BMJ Open. 2014; 4(1):e003954.

43. Coste J, Quinquis L, D'Almeida S, Audureau E. Smoking and health-related quality of life in the general population. Independent relationships and largedifferences according to patterns and quantity of smoking and to gender. PLoS One. 2014;9(3):e91562.

44. Jylha M. What is self-rated health and why does it predict mortality? Towards a unified conceptual model. Soc Sci Med. 2009;69:307-16.

45. Hirve S, Verdes E, Lele P, Juvekar S, Blomstedt Y, Tollman SM, Wall S, Chatterji S, Ng N: Evaluating reporting heterogeneity in self-rated health among adults aged 50 years and above in India: An anchoring vignettes analytic approach. J Aging Health. 2014;26(6):1015-31

46. Hirve S, Juvekar S, Sambhudas S, Lele P, Blomstedt $Y$, Wall S, et al. Does selfrated health predict death in adults aged 50 years and above in India? Evidence from a rural population under health and demographic surveillance. Int J Epidemiol. 2012;41:1719-27.

47. Ng N, Hakimi M, Santosa A, Byass P, Wilopo S, Wall S. Is self-rated health an independent index for mortality among older people in Indonesia? PLoS Med. 2012;7(4):8

48. Ng N, Kowal P, Kahn K, Naidoo N, Abdullah S, Bawah A, et al. Health inequalities among older men and women in Africa and Asia: evidence from eight health and demographic surveillance system sites in the INDEPTH WHO-SAGE study. Glob Health Action. 2010;3:5420;Suppl 2(INDEPTH WHO-SAGE Supplement):96-107. doi:10.3402/gha.v3i0.5420

49. Rubenstein LZ. Falls in older people: epidemiology, risk factors and strategies for prevention. Age Ageing. 2006:35(S2):ii37-41.

50. King G, Murray CJ, Salomon JA, Tandon A. Enhancing the validity and crosscultural comparability of measurement in survey research. Am Polit Sci Rev. 2004:98:191-207.

51. Hirve S, Gómez OX, Oti S, Debpuur C, Juvekar S, Tollman SM, Blomstedt Y, Stig Wall S, Ng N: Use of anchoring vignettes to evaluate health reporting behavior amongst adults aged 50 years and above in Africa and Asia testing assumptions. Glob Health Action. 2013;6:21064. doi:10.3402/gha.v6i0. 21064

52. Danziger N. Rural women and migration. In: International Organization for Migration-IOM. 2008. p. 6.

53. Mudege NN, Ezeh AC. Gender, aging, poverty and health: survival strategies of older men and women in Nairobi slums. J Aging Stud. 2009;23:245-57.

54. Taffa N, Chepngeno G. Determinants of health care seeking for childhood illnesses in Nairobi slums. Trop Med Int Health. 2005;10(3):240-5. 
55. Mutisya E, Yarime M. Understanding the grassroots dynamics of slums in Nairobi: the dilemma of Kibera informal settlements. Int Trans J Eng Manag Appl Sci Technol. 2011;2:97-213.

56. Andreotti A, Minicuci N, Kowal P, Chatterji S. Multidimensional profiles of health status: an application of the Grade of Membership Model to the World Health Survey. PLoS One. 2009;4(2):14.

Submit your next manuscript to BioMed Central and we will help you at every step:

- We accept pre-submission inquiries

- Our selector tool helps you to find the most relevant journal

- We provide round the clock customer support

- Convenient online submission

- Thorough peer review

- Inclusion in PubMed and all major indexing services

- Maximum visibility for your research 